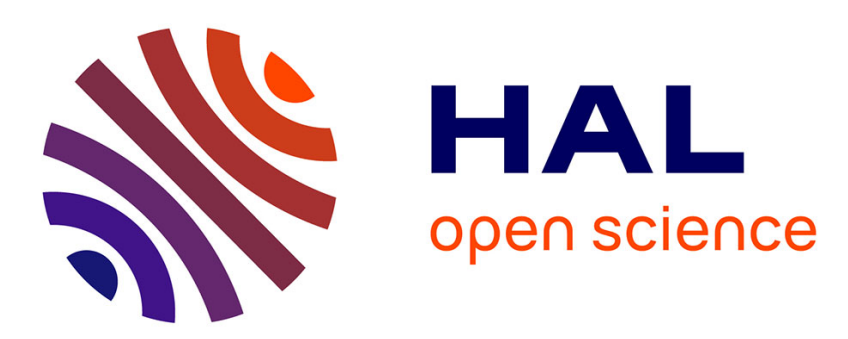

\title{
Variant c-type cytochromes as probes of the substrate specificity of the E. coli cytochrome c maturation $(\mathrm{Ccm})$ apparatus
}

\author{
James W. A. Allen, Elizabeth B Sawyer, Michael Ginger, Paul D Barker, \\ Stuart J Ferguson
}

\section{To cite this version:}

James W. A. Allen, Elizabeth B Sawyer, Michael Ginger, Paul D Barker, Stuart J Ferguson. Variant c-type cytochromes as probes of the substrate specificity of the E. coli cytochrome c maturation $(\mathrm{Ccm})$ apparatus. Biochemical Journal, 2009, 419 (1), pp.177-184. 10.1042/BJ20081999 . hal-00479105

\section{HAL Id: hal-00479105 \\ https://hal.science/hal-00479105}

Submitted on 30 Apr 2010

HAL is a multi-disciplinary open access archive for the deposit and dissemination of scientific research documents, whether they are published or not. The documents may come from teaching and research institutions in France or abroad, or from public or private research centers.
L'archive ouverte pluridisciplinaire HAL, est destinée au dépôt et à la diffusion de documents scientifiques de niveau recherche, publiés ou non, émanant des établissements d'enseignement et de recherche français ou étrangers, des laboratoires publics ou privés. 


\section{Variant c-type cytochromes as probes of the substrate specificity of the $E$. coli cytochrome $c$ maturation $(\mathrm{Ccm})$ apparatus}

James W. A. Allen ${ }^{\dagger}$, Elizabeth B. Sawyer ${ }^{\ddagger}$, Michael L. Ginger ${ }^{\S}$ Paul D. Barker ${ }^{\ddagger}$ and Stuart J. Ferguson $^{\dagger^{*}}$

†Department of Biochemistry, University of Oxford, South Parks Road, Oxford, OX1 3QU, United Kingdom, ${ }^{\star}$ Department of Chemistry, University of Cambridge, Lensfield Road, Cambridge, CB2 1EW, United Kingdom and ${ }^{\S}$ School of Health and Medicine, Division of Biomedical and Life Sciences, Lancaster University, Lancaster, LA1 4YQ, United Kingdom.

*Correspondence should be addressed to SJF: Tel +44 (0) 1865 275240; stuart.ferguson@bioch.ox.ac.uk

Keywords: $c$-type cytochrome, cytochrome c maturation, biogenesis, cytochrome $b_{562}$, posttranslational modification, heme-binding motif

Running Title: Assembly of variant $c$-type cytochromes by the E. coli Ccm system

Abbreviations: Ccm - cytochrome $c$ maturation; DTT - dithiothreitol; ESI-MS - electrospray ionisation mass spectrometry 


\section{Synopsis}

$c$-type cytochromes are normally characterised by covalent attachment of the iron cofactor heme to protein through two thioether bonds between the vinyl groups of the heme and the thiols of a Cys-Xxx-Xxx-Cys-His motif. In cells, the heme attachment is an enzyme catalysed, posttranslational modification. We have previously shown that co-expression of a variant of Escherichia coli cytochrome $b_{562}$ containing a $\mathrm{CXXCH}$ heme-binding motif with the $E$. coli cytochrome $c$ maturation $(\mathrm{Ccm})$ proteins resulted in homogeneous maturation of a correctly formed $c$-type cytochrome. In contrast, in the absence of the $\mathrm{Ccm}$ apparatus, the product holocytochrome was heterogeneous, the main species having heme inverted and attached through only one thioether bond. Here we use further variants of cytochrome $b_{562}$ to investigate the substrate specificity of the $E$. coli $\mathrm{Ccm}$ apparatus. The system can mature $c$-type cytochromes with $\mathrm{CCXXCH}, \mathrm{CCXCH}, \mathrm{CXCCH}$ and $\mathrm{CXXCHC}$ motifs, even though these are not found naturally and the extra cysteine might, in principle, disrupt the biogenesis proteins which must interact intricately with disulfide bond oxidising and reducing proteins in the $E$. coli periplasm. The $\mathrm{Ccm}$ proteins can also attach heme to motifs of the type $\mathrm{CX}_{n} \mathrm{CH}$ where $n$ ranges from 2 to 6 . For $n=3$ and 4, the heme attachment was correct and homogeneous, but for higher values of $n$ the holocytochromes displayed oxidative addition of sulfur and/or oxygen atoms associated with the covalent heme attachment process. The implications of our observations for the heme attachment reaction, for genome analyses and for the substrate specificity of the Ccm system are discussed. 


\section{Introduction}

Cytochrome $b_{562}$ is a hemoprotein naturally expressed in the periplasm of Escherichia coli [1]. It has a four $\alpha$-helix bundle structure [2,3] and its apoprotein (the heme free form) is also stable and structurally relatively ordered [4]. Other periplasmic cytochromes in E. coli are of the $c$-type, i.e. they contain heme(s) covalently attached to polypeptide through thioether bonds between the vinyl groups of heme and the cysteine sulfurs of a Cys-Xxx-Xxx-Cys-His peptide motif [5-8]. Biogenesis of $c$-type cytochromes in E. coli and many other Gram-negative bacteria is a complex post-translational process requiring multiple proteins. These are the cytochrome $c$ maturation $(\mathrm{Ccm})$ system (often called System I), CcmABCDEFGH, and various disulfide bond oxidising and reducing proteins including DsbA, DsbB, DsbD and TrxA $[5,7,9,10]$. The Dsb and Ccm systems are believed to work in series during cytochrome $c$ biogenesis such that as the unfolded apocytochrome is exported to the periplasm it is first oxidised by DsbA (whose oxidant is DsbB). The apocytochrome disulfide bond must be reduced before heme can be attached and this reduction is achieved by $\mathrm{CcmG}$ (with the possible involvement of $\mathrm{CcmH}$ ). $\mathrm{CcmG}$ is, in turn, reduced by the transmembrane protein DsbD, whose electron donor is the cytoplasmic TrxA [7, $9,11]$.

E. coli cytochrome $b_{562}$ can be altered by site directed mutagenesis such that it will form $c$-type cytochromes in the periplasm $[12,13]$. In cytochrome $b_{562}$, a histidine, residue 102 , is the proximal ligand to the heme iron; an analogous histidine is a virtually universal feature of both $b$ and $c$-type cytochromes. We constructed a R98C/Y101C variant of $b_{562}$ resulting in a CXXCH heme-binding motif [12]. When this protein was expressed in the presence of the E. coli Ccm proteins (also expressed from a plasmid) the product was a homogeneous bona fide c-type cytochrome with heme attached through two thioether bonds (which was characterised extensively by NMR). In contrast, $b_{562} \mathrm{CXXCH}$ expressed in the absence of the $\mathrm{Ccm}$ system resulted in heterogeneous products; in the main species, heme was attached by only one thioether bond and was inverted relative to its orientation in the Ccm matured cytochrome $[12,13]$. A large amount of apocytochrome was also present in each case. Cytochrome $b_{562}$ derivatives thus have major experimental advantages in the analysis of $c$-type cytochrome biogenesis: (i) the apoproteins and various forms of the holoprotein are, unlike almost all other apocytochromes $c$, stable in vivo and can be isolated. This allows for the positive detection of expressed proteins and confirmation of the correct mutations by mass spectrometry. (ii) Correctly and incorrectly matured $c$-type holocytochrome products can be readily assessed and distinguished using absorption spectroscopy (see $[13,14]$ for further details).

The E. coli Ccm apparatus has been shown to mature cytochromes $c$ from diverse prokaryotic and eukaryotic origins with many different folds and functions [e.g. 15-18]. However, it is essentially unable to mature potential $c$-type cytochromes with only one cysteine in the hemebinding motif, or those lacking the histidine of the CXXCH sequence $[14,19,20]$. In the present work we use other variants of $E$. coli cytochrome $b_{562}$ to further investigate the substrate specificity of the E. coli Ccm apparatus. Notably, there is great variation in the "XX" residues of the $\mathrm{CXXCH}$ motifs of $\mathrm{Ccm}$ matured $c$-type cytochromes. The only residue not naturally observed to date in either of the XX positions is cysteine. We hypothesised that this is because additional cysteine residues would inhibit or disrupt the $\mathrm{Ccm}$ biogenesis system which, see above, interacts intricately with the disulfide bond oxidation/reduction proteins of Gram-negative bacteria. Thus we have constructed variants of cytochrome $b_{562}$ containing $\mathrm{CCXXCH}, \mathrm{CCXCH}$, $\mathrm{CXCCH}$ and $\mathrm{CXXCHC}$ motifs and investigated their maturation by the E. coli $\mathrm{Ccm}$ proteins. The Ccm system can, at least in some organisms, mature $c$-type cytochromes with three or four residues between the cysteines of the heme-binding motif (e.g. Pseudomonas stutzeri cytochrome $c_{552}$ [21], cytochromes $c_{3}$ from sulfate reducing bacteria [22], and a variant of 
Rhodobacter sphaeroides cytochrome $c_{2}$ [23]). However, the specificity of the biogenesis system for such proteins is not clear, nor is there any evidence on possible limits for the number of " $\mathrm{X}$ " residues. Thus we have investigated maturation of a series of $b_{562}$ variants with amino acid insertions to create heme-binding motifs ranging from $\mathrm{CX}_{2} \mathrm{CH}$ to $\mathrm{CX}_{6} \mathrm{CH}$.

\section{Experimental}

Bacterial strains, plasmids and growth conditions.

Escherichia coli strain JCB387 (a AnirB Alac derivative of strain RV) [24], the kind gift of Professor Jeff Cole (University of Birmingham, UK), was used in all experiments. This strain was chosen because we have found in previous studies that it reliably produces large amounts of holocytochromes $c$ including $b_{562} \mathrm{CXXCH}$ (and also apocytochrome $b_{562} \mathrm{CXXCH}$ ), and to ensure consistency with our previous work [e.g. 13, 14, 19]. The plasmid for the R98C/Y101C (CXXCH heme-binding motif) variant of $E$. coli cytochrome $b_{562}$ was as described [12]. As required, cells were also transformed with plasmid pEC86 [15] encoding the $E$. coli cytochrome $c$ maturation genes, $c c m A B C D E F G H$. Transformants were initially grown on LB-agar plates with the appropriate antibiotics $\left(100 \mu \mathrm{g} \mathrm{ml}^{-1}\right.$ ampicillin in each case, plus $34 \mu \mathrm{g} \mathrm{m}{ }^{-1}$ chloramphenicol where pEC86 was co-transformed). Single colonies were picked into $500 \mathrm{ml}$ 2xTY medium (16 $\mathrm{g} \mathrm{l}^{-1}$ peptone, $10 \mathrm{~g} \mathrm{l}^{-1}$ yeast extract and $5 \mathrm{~g} \mathrm{l}^{-1} \mathrm{NaCl}$ ), supplemented with 1 mM IPTG, in 2.51 flasks. Cultures were grown at $37^{\circ} \mathrm{C}$ with shaking at $200 \mathrm{rpm}$ for $20 \mathrm{~h}$, before harvesting. Such aerobic growth conditions repress expression of the FNR regulated endogenous Ccm proteins of E. coli.

The sequence of wild type cytochrome $b_{562}$ around the site of incorporation of the CXXCH heme-binding motif [12] is TRNAYHQ (where the histidine, the proximal ligand to the heme iron, is residue 102). Thus, after introduction of the CXXCH motif, the sequence is TCNACHQ. The following plasmids encoding new $b_{562}$ variants with additional cysteines around the heme binding motif were prepared using the Quikchange method (Stratagene) and Pfx polymerase (Invitrogen): T97C/R98C/Y101C (b $562 \mathrm{CCXXCH}) ; \mathrm{R} 98 \mathrm{C} / \mathrm{N} 99 \mathrm{C} / \mathrm{Y} 101 \mathrm{C} \quad\left(b_{562} \mathrm{CCXCH}\right)$; R98C/A100C/Y101C ( $\left.b_{562} \mathrm{CXCCH}\right) ; \mathrm{R} 98 \mathrm{C} / \mathrm{Y} 101 \mathrm{C} / \mathrm{Q} 103 \mathrm{C}\left(b_{562} \mathrm{CXXCHC}\right)$. Other variants were prepared from $b_{562} \mathrm{CXXCH}$ by inserting amino acids (see Results) between residues 100 and 101 of the starting sequence to give: CNAACH $\left(b_{562} \mathrm{CX}_{3} \mathrm{CH}\right), \mathrm{CNAAGCH}\left(b_{562} \mathrm{CX}_{4} \mathrm{CH}\right)$, CNAAGSCH $\left(b_{562} \mathrm{CX}_{5} \mathrm{CH}\right)$ and CNAAGSQCH $\left(b_{562} \mathrm{CX}_{6} \mathrm{CH}\right)$. The presence of the desired mutations and the lack of secondary mutations were confirmed both by DNA sequencing and, as a consequence of the characterisation of the purified proteins, by mass spectrometry (see Results).

\section{Cell fractionation and biochemical procedures.}

Periplasmic fractions were obtained from cells using procedures described previously [19]. Cytochrome content was determined by recording absorption spectra of the crude or purified periplasmic fractions to which a small amount of dithionite had been added to reduce the cytochromes. E. coli produces small amounts of endogenous $c$-type cytochromes in the periplasm in our growth conditions; for details of how these were handled during data analysis see [13]. Cytochrome $b_{562}$ derivatives were initially purified on a DEAE-Sepharose anion exchange column. Chromatography was conducted at room temperature in $50 \mathrm{mM}$ Tris- $\mathrm{HCl}$ buffer, pH 8.0. The column (Amersham Pharmacia XK26/20 with a resin bed volume of $70 \mathrm{ml}$ ) was eluted with a $0-0.5 \mathrm{M} \mathrm{NaCl}$ gradient at a flow rate of $9 \mathrm{ml} \mathrm{min}^{-1}$ and $7 \mathrm{ml}$ fractions were collected. Apocytochrome $b_{562}$ eluted before, and largely separated from, the holocytochrome during this chromatographic step. Apocytochrome-containing fractions were identified from their absorption spectra following the addition of dithiothreitol (DTT) and heme (producing a species with a characteristic $b$-type cytochrome spectrum), and were nearly pure as judged by 
SDS-PAGE. Where necessary, the spectrophotometrically purest holocytochrome fractions were pooled, diluted four-fold and loaded onto a Q-Sepharose column (XK26/20), which was eluted with a $0-0.25 \mathrm{M} \mathrm{NaCl}$ gradient in the same buffer and conditions. After this step, the holocytochrome $b_{562}$ derivatives were electrophoretically pure.

SDS-PAGE was conducted using the NuPage system (Invitrogen) with 10\% Bis-Tris gels and MES running buffer, used according to the manufacturer's protocols. Samples for analysis by SDS-PAGE did not include reductant unless stated. Gels were stained for protein using Simply Blue Safestain (Invitrogen) according to the manufacturer's protocol. Gels were stained for proteins with heme covalently bound as follows: after electrophoresis, the gel was soaked in 50 $\mathrm{mM}$ sodium acetate solution $(\mathrm{pH} \mathrm{5)}$ for $30 \mathrm{~min}$ with gentle rocking, after which $33 \mathrm{mg}$ of 3,3',5,5'-Tetramethylbenzidine (TMBZ) dissolved in $30 \mathrm{ml}$ methanol were added. The gel was allowed to incubate for a further $10 \mathrm{~min}$, after which $600 \mu \mathrm{l}$ of $30 \%$ hydrogen peroxide were added. The stain developed in $<10 \mathrm{~min}$. Ellman's reagent was used according to Riddles et al [25]. Reduced pyridine hemochrome spectra were obtained as described by Bartsch [26]. Electrospray ionisation mass spectrometry was performed on a Micromass Bio-Q II-2S triple quadrupole atmospheric pressure instrument equipped with an electrospray interface. Samples were introduced via a loop injector as a solution $\left(20 \mathrm{pmol}^{-1} \mathrm{l}^{-1}\right.$ in $1: 1$ water:acetonitrite $/ 0.2 \%(\mathrm{v} / \mathrm{v})$ formic acid) at a flow rate of $10 \mu \mathrm{min}^{-1}$. Data were analysed using the maximum entropy based component of the MassLynx suite of software (Micromass) [27].

NMR spectra of $\mathrm{Ccm}$ matured holocytochrome $b_{562} \mathrm{CCXXCH}$ protein were collected as described previously [12] using a Bruker DRX 500 spectrometer. All spectra were acquired at $300 \mathrm{~K}$. Data processing was as described previously [12] except that it was performed using XWINNMR (Bruker) or SPARKY. Samples contained $0.5 \mathrm{mM}$ protein in $20 \mathrm{mM}$ potassium phosphate buffer in $\mathrm{D}_{2} \mathrm{O}, \mathrm{pH}^{*} 6.6$, and $0.5 \mathrm{M} \mathrm{KCl}$. The protein was reduced by addition of sodium dithionite to $5 \mathrm{mM}$ from anaerobic stock solutions in the same buffer.

\section{Results}

The effect of extra cysteine residues around the heme binding motif

Absorption and reduced pyridine hemochrome spectra of crude periplasmic extracts from $E$. coli cells co-transformed with a plasmid for $b_{562} \mathrm{CCXXCH}, \mathrm{CCXCH}, \mathrm{CXCCH}$ or $\mathrm{CXXCHC}$ and a plasmid expressing the $\mathrm{ccm}$ genes (Figure 1; Table 1) were indistinguishable from those of extracts of cells producing correctly (i.e. $\mathrm{Ccm}$ ) matured $b_{562} \mathrm{CXXCH}$ [13]. Each construct included the natural signal sequence of cytochrome $b_{562}$ which directs the apoprotein to the periplasm where both wild type $b_{562}$ and all Gram-negative bacterial cytochromes $c$ are naturally assembled. Each product holocytochrome had absorbance $\alpha$ and $\beta$-band maxima at 556 and 526 $\mathrm{nm}$ respectively, and the pyridine hemochrome $\alpha$-band maximum at $550 \mathrm{~nm}$ (Figure 1; Table $1)^{1}$. These results were the same for the purified cytochromes, which were shown chromatographically to be $\geq 95 \%$ homogeneous in each case (based on absorption and hemochrome data). The spectral data are characteristic of $c$-type cytochrome variants of cytochrome $b_{562}$ with heme bound to protein through two thioether bonds (see e.g. [13]). The holocytochrome yields were high (ca. 5-6 mg holocytochrome $c$ per gram of wet cells) for each variant (calculated by assuming an extinction coefficient of $22900 \mathrm{M}^{-1} \mathrm{~cm}^{-1}$ at $556 \mathrm{~nm}$, as for

\footnotetext{
${ }^{1}$ Reduced pyridine hemochrome spectra provide information about the nature of any modifications to the heme (such as covalent attachment to protein through thioether bonds), but the spectrum is otherwise independent of the protein environment because the protein is dentaured. Their absorption maxima thus give strong evidence about proper or improper maturation of a $c$-type cytochrome - for a cytochrome with heme attached through two thioether bonds the $\alpha$-band maximum is at $549-550 \mathrm{~nm}$, for attachment through one thioether bond it is at 552-3 nm, and for a $b$-type cytochrome (no covalent attachment) it is at $556 \mathrm{~nm}$.
} 
Component II described by Barker et al $[12,13])$. As was the case with $b_{562} \mathrm{CXXCH}$, a large amount of apo- (heme free) cytochrome could be observed (by adding heme, DTT and dithionite to periplasmic extracts to generate reduced $b$-type cytochromes [13]) following expression of each of the $\mathrm{CCXXCH}, \mathrm{CCXCH}, \mathrm{CXCCH}$ or $\mathrm{CXXCHC}$ cytochromes.

When the $b_{562}$ variants containing three cysteines were analysed using SDS-PAGE gels stained for covalently bound heme, two major bands were apparent in each case, one corresponding to monomer (running at the same molecular weight as the positive control, purified holocytochrome $b_{562} \mathrm{CXXCH}$ ) and one corresponding to dimer. When DTT was added for $c a$. $30 \mathrm{~min}$ after the samples were boiled, but before running the gel, the amount of dimer dramatically decreased. These data suggest that these variants can all form disulfide bond linked dimers. Electrospray ionisation mass spectrometry (ESI-MS) of holocytochrome purified by DEAE-Sepharose chromatography showed, for each "extra-cysteine" $b_{562}$ variant $\left(b_{562} \mathrm{CCXXCH}, \mathrm{CCXCH}\right.$, $\mathrm{CXCCH}$ and $\mathrm{CXXCHC}$ ), peaks with masses corresponding to holocytochrome monomer, apocytochrome-holocytochrome dimer (i.e. protein dimer with one heme attached) and holocytochrome-holocytochrome dimer (Supplementary Table 1$)^{2}$. The dimerisations probably occurred more slowly than heme attachment to the cytochromes, possibly during cell fractionation and protein isolation; it seems unlikely that the $\mathrm{Ccm}$ system could attach heme to a dimer already formed via cysteine residues adjacent to, or within, the $\mathrm{CXXCH}$ heme-binding motif.

In the absence of expression of the $\mathrm{Ccm}$ proteins, incorrectly matured holocytochrome was observed for each of the $b_{562}$ extra cysteine variants judging by absorption spectra, pyridine hemochrome spectra and SDS-PAGE gels (Figure 1; Table 1). Absorption maxima were at 558$560 \mathrm{~nm}$ and 528-529 $\mathrm{nm}$ with pyridine hemochrome maxima at 552-553 nm. Very similar observations were previously made for $b_{562} \mathrm{CXXCH}$ matured in the absence of the $\mathrm{Ccm}$ proteins $[12,13]$ and represent heme attachment apparently without the aid of enzyme catalysis. The yield for the cytochrome $b_{562}$ "extra cysteine" variants expressed in the absence of the Ccm proteins ranged from 1.5-2.8 mg holocytochrome per gram of wet cells (calculated assuming an extinction coefficient of $25800 \mathrm{M}^{-1} \mathrm{~cm}^{-1}$ for the reduced $\alpha$-band peak in each case, as for Component I in [12]). Thus, for each holocytochrome, the yield was lower than when the corresponding cytochrome was matured by the $\mathrm{Ccm}$ apparatus (see above and Table 1). SDSPAGE gels stained for protein or for covalently bound heme for each of the triple cysteine variants expressed in the absence of the $\mathrm{Ccm}$ proteins showed the formation of dimers, trimers and small amounts of tetramer which were predominantly DTT reducible, as well as monomers. This polymerisation (as well as the pyridine hemochrome maxima) is consistent with non-Ccm dependent heme attachment to $b_{562} \mathrm{CXXCH}$ being through only a single cysteine-heme bond $[12,13]$ (hence the variants with three cysteines being able to oligomerise).

For the Ccm matured cytochrome $b_{562}$ extra cysteine variants, the heme could, in principle, be attached to any two of the three cysteines. The absorption spectroscopic methods described so far demonstrate that the heme is attached to two of them (i.e. that the two original heme vinyl groups are both saturated), but cannot determine which cysteines. This is of particular relevance for the $\mathrm{CCXXCH}$ variant, since the $\mathrm{Ccm}$ proteins can attach heme readily to both $\mathrm{CXXCH}$ and $\mathrm{CXXXCH}$ motifs (including a cytochrome $b_{562} \mathrm{CX}_{3} \mathrm{CH}$ variant (see below and Figure 2A)). NMR data indicate that the vast majority of the heme attachment to the CCXXCH protein by the $\mathrm{Ccm}$ apparatus was to the $\mathrm{C} \mathbf{C X X C H}$ cysteines, rather than to $\mathrm{CCXXCH} .{ }^{1} \mathrm{H}$ NMR spectra (Figure 3 ) of the purified holoprotein are consistent with one predominant species. The heme proton

\footnotetext{
${ }^{2}$ Apocytochrome-apocytochrome dimers were also observed (Supplementary Table 1).
} 
resonances from this species, together with resonances from some amino acid side-chain protons of residues in the vicinity of the heme, were assigned using homonuclear NOESY and TOCSY experiments (Figure 3B) as previously described $[12,13]$. These chemical shifts are compared with those of $\mathrm{Ccm}$ matured holocytochrome $b_{562} \mathrm{CXXCH}[12,13]$ in Supplementary Table 2. The close similarity of these resonances from the two proteins suggests that the structure at the heme attachment sites, and the electronic structure of the heme, is very similar in the CXXCH and $\mathrm{CCXXCH}$ cytochromes. In the spectra of the reduced (Fe(II)) $\mathrm{CCXXCH}$ protein, one major resonance from the $\varepsilon$-methyl group of the heme iron ligand Met-7 is observed (Figure $3 \mathrm{~A}$ ), Also observed are resonances (marked by asterisks in Figure 3A) from the $\varepsilon$-methyl group of the same residue but in other, very closely related, species. These species are not abundant enough to be able to identify the origin of this alteration to the chemical shift of the ligand methyl protons, but such alternative species have been observed before both in cytochromes $b_{562}$ [28] and cytochrome $c_{552}$ from Hydrogenobacter thermophilus [29], and we do not believe that they arise from species with alternative modes of heme attachment. Indeed, in the NOESY and TOCSY NMR spectra of Ccm matured holocytochrome $b_{562} \mathrm{CCXXCH}$ (Figure 3B) we can find only the expected two resonances from protons at the 2- and 4-methine positions of the heme. Highlighted in the expanded region of Figure 3B are the TOCSY cross-peaks from the 2- and 4methine and methyl heme substituents that result from the reaction of the cysteine residues of the apocytochrome heme-binding motif with the heme 2- and 4-vinyl groups. There is no heterogeneity revealed in this region of the spectrum and the chemical shifts of the relevant protons are very close to those reported in our earlier work for $\mathrm{Ccm}$ matured cytochrome $b_{562}$ CXXCH (Supplementary Table 2; Component II in $[12,13]$ ), which has the same stereo- and regio-specific covalent attachment of heme as is observed in all natural $c$-type cytochromes for which relevant data are available. The sensitivity of our NMR experiments is such that we can therefore confidently say that at least $90 \%$ of the protein has heme attached to the $\mathrm{CXXXCH}$ motif, but we cannot rule out that $<10 \%$ has attachment to the alternative $\mathbf{C C X X C H}$ cysteines. Protein digestion followed by HPLC isolation of peptides, cysteine derivatisation and N-terminal sequencing suggested some heme attachment to both the first and second cysteines of the CCXXCH motif. This analysis was not quantitative, but it was consistent with the significant majority of heme attachment being to the $\mathrm{C} \mathbf{C X X C H}$ cysteines. It is possible that oxidation of the $\mathrm{CCXXCH}$ apocytochrome by the E. coli periplasmic disulfide oxidase DsbA, and/or interaction with the thiol containing proteins of the $\mathrm{Ccm}$ system $(\mathrm{CcmG}, \mathrm{CcmH})$ selects preferentially the $\mathrm{CXXCH}$ cysteines for heme attachment.

The effect of extra residues between the cysteines of the heme-binding motif

We also constructed variants of $E$. coli cytochrome $b_{562}$ with potential $\mathrm{CX}_{3} \mathrm{CH}, \mathrm{CX}_{4} \mathrm{CH}, \mathrm{CX}_{5} \mathrm{CH}$ and $\mathrm{CX}_{6} \mathrm{CH}$ heme-binding motifs (" $\mathrm{CX}_{n} \mathrm{CH}$ variants"). This was achieved by inserting additional amino acids between the cysteines of the $b_{562} \mathrm{R} 98 \mathrm{C} / \mathrm{Y} 101 \mathrm{C}$ (i.e. $\mathrm{CXXCH}$ ) variant. The inserted amino acids were chosen so as to avoid bulky side chains and proline, and to include a mixture of polar and somewhat hydrophobic residues; we did not try to optimise the selection of inserted residues. The resulting sequences were CNAACH $\left(b_{562} \mathrm{CX}_{3} \mathrm{CH}\right), \mathrm{CNAAGCH}\left(b_{562} \mathrm{CX}_{4} \mathrm{CH}\right)$, CNAAGSCH $\left(b_{562} \mathrm{CX}_{5} \mathrm{CH}\right)$ and CNAAGSQCH $\left(b_{562} \mathrm{CX}_{6} \mathrm{CH}\right)$.

Each $\mathrm{CX}_{n} \mathrm{CH}$ variant was expressed with the Ccm proteins and the holocytochromes were purified. In each case, the absorption and pyridine hemochrome spectra of the resulting holocytochromes were indicative of heme attachment through two thioether bonds (Figure 2A; Table 2). The yield is calculated assuming all the holocytochromes have the same extinction coefficients as Ccm matured cytochrome $b_{562} \mathrm{CXXCH}$ (Component II in [12]; see also [13]). 
Notably, the $\mathrm{CX}_{3} \mathrm{CH}$ and $\mathrm{CX}_{4} \mathrm{CH}$ variants were in each measured respect, including by mass spectrometry, properly matured $c$-type cytochromes (Figure 2A; Table 2). It is also clear that the $\mathrm{Ccm}$ system acted upon the $\mathrm{CX}_{5} \mathrm{CH}$ and $\mathrm{CX}_{6} \mathrm{CH}$ apocytochromes. The presence of the $\mathrm{Ccm}$ proteins increased the holocytochrome yield and produced absorption and pyridine hemochrome spectra characteristic of double thioether bond attachment of heme to protein (Figure 2A; Table 2). In the absence of the $\mathrm{Ccm}$ proteins, the $b_{562} \mathrm{CX}_{5} \mathrm{CH}$ and $\mathrm{CX}_{6} \mathrm{CH}$ holocytochromes both showed the characteristics of uncatalysed heme attachment through a single thioether bond (Figure 2B; Table 2) $[12,13]$. However, even though the $\mathrm{Ccm}$ system matured the $\mathrm{CX}_{5} \mathrm{CH}$ and $\mathrm{CX}_{6} \mathrm{CH}$ cytochromes, it is clear from the mass spectra that the products did not show the usual ultra-high level of quality control observed for the $\mathrm{Ccm}$ apparatus, and species of different mass were observed in various proportions.

Analysis by ESI-MS showed that for the $\mathrm{CX}_{5} \mathrm{CH}$ variant, $\sim 60 \%$ of the holocytochrome was of the expected molecular weight with $\sim 10 \%$ at 32 Da above the expected value and $\sim 30 \% 64 \mathrm{Da}$ heavier than expected (Table 2). In the $\mathrm{CX}_{6} \mathrm{CH}$ case, very little of the holocytochrome was at the expected mass; the major species $(\sim 55 \%)$ was 64 Da above the expected weight with the remainder at $+48 \mathrm{Da}(\sim 30 \%)$ or $+32 \mathrm{Da}$. Note that the relative populations of each species given are estimates based on the intensities of peaks in the transformed mass spectrum, assuming that each form of the protein flies equally well in the electrospray experiment; the precise proportions also varied between different holocytochrome preparations ${ }^{3}$. The peaks at heavier masses than expected presumably arise from modified holocytochromes. These modifications may result from the addition of sulfur (32 Da) and/or oxygen $(16 \mathrm{Da})$ atoms in some proportion(s), but the method of mass spectrometry used is not precise enough to distinguish between these possibilities. The likely sites of any oxidation in the cytochromes are the cysteine and methionine residues.

Notably, mass spectra of apoproteins containing $\mathrm{CX}_{5} \mathrm{CH}$ and $\mathrm{CX}_{6} \mathrm{CH}$ sequences purified from cells also expressing the $\mathrm{Ccm}$ proteins from plasmid pEC86 did not show any evidence of significant extra mass $(\leq 10 \%$ of the protein), suggesting that the oxidation observed for the holocytochromes (Table 2) is associated with, or a result of, heme attachment. Incubation of apocytochrome $b_{562} \mathrm{CX}_{5} \mathrm{CH}$ and $\mathrm{CX}_{6} \mathrm{CH}$ with DTT before recording the mass spectra resulted in mass increases of and 2.1 and $1.8 \mathrm{Da}$ respectively, indicating that reduction of a disulfide bond within the apoprotein had taken place. Analysis with Ellman's reagent confirmed this, showing that $>95 \%$ of the cysteine in the purified apocytochromes $\mathrm{CX}_{5} \mathrm{CH}$ and $\mathrm{CX}_{6} \mathrm{CH}$ was present in disulfide bonds (as seen previously for the CXXCH variant [13]). For the analysis with Ellman's reagent, the apocytochrome concentration was estimated from the theoretical extinction coefficient at $280 \mathrm{~nm}$ calculated from the protein sequence, and by titrating the reduced apoprotein with heme (to form a $b$-type cytochrome) until it was saturated.

\section{Discussion}

Our data suggest that cytochromes with $\mathrm{CCXXCH}, \mathrm{CCXCH}, \mathrm{CXCCH}$ and $\mathrm{CXXCHC}$ motifs can be matured by the E. coli Ccm apparatus (Figure 1; Table 1). Thus, our hypothesis that extra cysteine residues in or around the consensus $\mathrm{CXXCH}$ heme-binding motif would disrupt the biogenesis proteins has proven incorrect. These results therefore beg the question why are extra cysteine residues not observed in the "XX" positions of, or adjacent to, the CXXCH motifs of natural $c$-type cytochrome heme-binding motifs? More generally, why are cysteines other then those in the CXXCH motif rare overall in the soluble domains of $c$-type cytochromes? Given that our results suggest that such proteins could be matured (at least by the type of cytochrome $c$

\footnotetext{
${ }^{3}$ In the extreme case, $\sim 75 \%$ of the $\mathrm{CX}_{5} \mathrm{CH}$ holocytochrome had the correct mass.
} 
biogenesis apparatus investigated here), one likely explanation is that free cysteine thiols could react with heme iron and promote destructive chemistry. In particular, a thiol can be oxidised by ferric heme to generate a thiyl radical which could then attack the porphyrin ring or the protein. Such reactions have been observed in various conditions [e.g. 30-33]. Clearly this is undesirable in the cell where heme proteins have the potential to do significant oxidative damage and their formation and properties must be tightly controlled. Another factor is the potential for dimerisation via formation of disulfide bonds in the oxidising environment of the bacterial periplasm, which was clearly apparent in each of our mutants containing extra cysteines (e.g. Supplementary Table 1), and the potential to form mixed disulfides with other periplasmic thiol proteins. Any functionally undesirable consequences of such interactions can be avoided if there are no free cysteine residues available to form disulfide bonds. Thirdly, as our data for the $\mathrm{CCXXCH}$ variant of cytochrome $b_{562}$ suggests, extra cysteine residues around the heme binding motif introduce the possibility of heterogeneity in heme attachment, which could have negative consequences for the function of $c$-type cytochromes and hence for the cell.

It is also clear from our data that the Ccm system can act on apocytochromes with at least six residues between the heme binding cysteines (Figure 2A; Table 2). All methods used showed that the $\mathrm{CX}_{3} \mathrm{CH}$ and $\mathrm{CX}_{4} \mathrm{CH}$ variants were matured properly. Examples of such heme-attachment motifs are, although rare, known in nature [e.g. 21, 22; reviewed in 6]. Maturation of the cytochrome $b_{562} \mathrm{CX}_{5} \mathrm{CH}$ and $\mathrm{CX}_{6} \mathrm{CH}$ variants was also enhanced by the $\mathrm{Ccm}$ apparatus (Figure 2 ), although in these cases the products were neither perfect nor homogeneous. The $\mathrm{Ccm}$ matured $\mathrm{CX}_{n} \mathrm{CH}$ holocytochromes had absorption $\alpha$-band maxima at $555 \mathrm{~nm}$ and pyridine hemochrome $\alpha$-bands at $549.5 \mathrm{~nm}$ (Figure 2A) both characteristic of heme attachment to protein with saturation of both heme vinyl groups. In contrast, the equivalent cytochromes produced in the absence of the $\mathrm{Ccm}$ proteins had red shifted spectra, indicative of (incorrect) heme attachment through only one thioether bond (Figure 2B) (reminiscent of our earlier observations for the $\mathrm{CXXCH}$ variant $[12,13])$. Moreover, the $\mathrm{Ccm}$ matured holocytochromes were present at 6-7 fold higher yields than those produced in the absence of the Ccm proteins (Table 2). Nevertheless, ESI-MS revealed additional mass in $\leq 40 \%$ of the $\mathrm{Ccm}$ matured $\mathrm{CX}_{5} \mathrm{CH}$ holocytochrome and $\sim 100 \%$ of the $\mathrm{CX}_{6} \mathrm{CH}$ equivalent. The holocytochromes formed by these variants in the absence of the $\mathrm{Ccm}$ proteins are far more heterogeneous and despite extensive attempts to do so, we have been unable to obtain consistent mass data by ESI-MS of these samples. More detailed analysis will be required to identify the origin of the extra mass in the modified holocytochromes, but this represents a challenging problem since relevant isotopic labels $\left({ }^{18} \mathrm{O},{ }^{35} \mathrm{~S}\right)$ cannot be incorporated specifically in the cytochromes.

Our results are a rare, clear, example of the Ccm system failing to exercise ultra high-fidelity quality control in the maturation of a $c$-type cytochrome. One interpretation of the data is that a $\mathrm{CX}_{4} \mathrm{CH}$ motif is the upper limit for the $\mathrm{Ccm}$ system to be able to mature the resulting $c$-type cytochrome with perfect control. However, the Ccm system may be able to properly mature natural (evolved) cytochromes with five (or more) residues between the heme binding cysteines since the imperfections in our cytochrome $b_{562}$ variants were small (Table 2; Figure 2A) and, in the $\mathrm{CX}_{5} \mathrm{CH}$ holocytochrome, affected $\leq 40 \%$ of the protein. Variations in the Ccm proteins themselves in organisms with putative long $\mathrm{CX}_{n} \mathrm{CH}$ heme binding motifs could also alleviate any constraint imposed by the $E$. coli $\mathrm{Ccm}$ apparatus which naturally processes $\mathrm{CXXCH}$ as its only (known) endogenous $c$-type cytochrome heme-binding motif. Simon and co-workers recently showed than an exceptional cytochrome, MccA from Wolinella succinogenes, has a $\mathrm{CX}_{15} \mathrm{CH}$ heme-binding motif, but in that case a special, apparently dedicated, System II biogenesis protein was also required for the heme attachment [34]. However, they also pointed out that in Shewanella species, organisms which use the $\mathrm{Ccm}$ system to mature their $c$-type cytochromes, 
the gene for a MccA homologue is near to genes encoding $\mathrm{CcmF}$ and $\mathrm{CcmH}$ homologues, which they postulated are required for heme attachment to the $\mathrm{CX}_{15} \mathrm{CH}$ motif of MccA. Their results in combination with ours have important implications for genome analyses. It has generally been assumed that the defining requirements for a protein to be a $c$-type cytochrome are a periplasmic (or extracytoplasmic) signal sequence and one or more CXXCH motifs. It is now clear that the latter is not a sufficient basis on which to discriminate and motifs of the type $\mathrm{CX}_{n} \mathrm{CH}$ should more generally be considered as plausible cytochromes $c$. On the other hand, the $c$-type cytochromes found in the protein structure databases, selected essentially randomly, indicate that heme attachment motifs other than $\mathrm{CXXCH}$ are rare.

The chemical origin of the extra mass we observed for our $\mathrm{Ccm}$ matured $\mathrm{CX}_{5} \mathrm{CH}$ and $\mathrm{CX}_{6} \mathrm{CH}$ holocytochromes (Table 2) is unclear. However, the modification appears related to the covalent attachment of heme since the corresponding purified apocytochromes showed little evidence of oxidation. If the modification occurred, as seems likely, during the heme attachment process rather than afterwards, it may reflect kinetic competition in the E. coli periplasm between the chemical processes that lead to incorporation of the extra mass and the heme attachment reaction. No increased mass holocytochrome species was observed where $n=2,3$ or 4; only $40 \%$ of the protein showed extra mass for $n=5$, but $\sim 100 \%$ did for $n=6$. Thus, heme attachment may be relatively fast when $n$ is small and slower as $n$ increases. Notably, the overall $\mathrm{Ccm}$ matured holocytochrome yield decreased as $n$ increased (Table 2).

Our results reaffirm that the specificity determinant of the Ccm system is still, apparently, simply the two cysteines and the histidine of the heme binding motif. The spacing between the cysteines does not affect the ability of the Ccm system to act on the apocytochrome, nor do the residues in the XX positions of the heme binding motif. In nature, there is great variation in the "XX" residues of the $\mathrm{CXXCH}$ motifs of $\mathrm{Ccm}$ matured c-type cytochromes. These residues can be charged (e.g. Lys), bulky (e.g. Trp), or even proline. Indeed, the only residue not naturally observed to date in either of the XX positions is cysteine. However, as shown here, the Ccm system can properly mature variant $c$-type cytochromes with $\mathrm{CCXXCH}, \mathrm{CCXCH}, \mathrm{CXCCH}$ and CXXCHC motifs. Given the choice of two cysteines, e.g. in a CCXXCH motif, the Ccm system clearly selects for heme attachment the N-terminal Cys residue that is separated by two "Xxx" residues from the $\mathrm{C}$-terminal cysteine of the heme-biding motif. We have recently discussed possible mechanistic reasons for the need for two cysteines and for the histidine of the motif elsewhere [18].

\section{Acknowledgements}

JWAA is a BBSRC David Phillips Fellow and MLG is a Royal Society University Research Fellow. We thank Professor David J. Richardson, Antony C. Willis and Christopher J. Andrews for very helpful discussions.

\section{Funding}

This work was supported by the Biotechnology and Biological Sciences Research Council [grant numbers BB/C508118/ and BBD019753/1] and the Engineering and Physical Sciences Research Council [studentship to EBS]. 


\section{References}

1. Itagaki, E., and Hager, L. P. (1966) Studies on cytochrome $b_{562}$ of Escherichia coli. I. Purification and crystallization of cytochrome $b_{562}$. J. Biol. Chem. 241, 3687-3695

2. Hamada, K., Bethge, P. H., and Mathews, F. S. (1995) Refined structure of cytochrome $b_{562}$ from Escherichia coli at $1.4 \AA$ Å resolution. J. Mol. Biol. 247, 947-962

3. Mathews, F. S., Bethge, P. H., and Czerwinski, E. W. (1979) The structure of cytochrome $b_{562}$ from Escherichia coli at $2.5 \AA$ resolution. J. Biol. Chem. 254, 1699-1706

4. Feng, Y., Sligar, S. G., and Wand, A. J. (1994) Solution structure of apocytochrome $b_{562}$. Nature Struct. Biol. 1, 30-34

5. Thony-Meyer, L. (2000) Haem-polypeptide interactions during cytochrome $c$ maturation. Biochim. Biophys. Acta. 1459, 316-324

6. Barker, P. D., and Ferguson, S. J. (1999) Still a puzzle: why is haem covalently attached in ctype cytochromes? Structure Fold. Des. 7, R281-290

7. Allen, J. W. A., Daltrop, O., Stevens, J. M., and Ferguson, S. J. (2003) C-type cytochromes: diverse structures and biogenesis systems pose evolutionary problems. Philos. Trans. Roy. Soc. Lond. B Biol. Sci. 358, 255-266

8. Stevens, J. M., Daltrop, O., Allen, J. W. A., and Ferguson, S. J. (2004) C-type cytochrome formation: chemical and biological enigmas. Acc. Chem. Rev. 37, 999-1007.

9. Fabianek, R. A., Hennecke, H., and Thony-Meyer, L. (2000) Periplasmic protein thiol:disulfide oxidoreductases of Escherichia coli. FEMS Microbiol. Rev. 24, 303-316

10. Page, M. D., Sambongi, Y., and Ferguson, S. J. (1998) Contrasting routes of c-type cytochrome assembly in mitochondria, chloroplasts and bacteria. Trends Biochem. Sci. 23, 103-108

11. Turkarslan, S., Sanders, C., Ekici, S., and Daldal, F. (2008) Compensatory Thio-redox Interactions Between DsbA, CcdA and CcmG Unveil the Apocytochrome $c$ Holdase Role of CcmG During Cytochrome c Maturation. Mol. Micro. In press.

12. Barker, P. D., Nerou, E. P., Freund, S. M. V., and Fearnley, I. M. (1995) Conversion of cytochrome $b_{562}$ to $c$-type cytochromes. Biochemistry 34, 15191-15203

13. Allen, J. W. A., Barker, P. D., and Ferguson, S. J. (2003) A cytochrome $b_{562}$ variant with a ctype cytochrome $\mathrm{CXXCH}$ heme-binding motif as a probe of the Escherichia coli cytochrome $c$ maturation system. J. Biol. Chem. 278, 52075-52083

14. Allen, J. W. A., Leach, N., and Ferguson, S. J. (2005) The histidine of the $c$-type cytochrome $\mathrm{CXXCH}$ haem-binding motif is essential for haem attachment by the Escherichia coli cytochrome $c$ maturation $(\mathrm{Ccm})$ apparatus. Biochem. J. 389, 587-592 
15. Arslan E., Schulz, H., Zufferey, R., Kunzler, P., and Thöny-Meyer, L. (1998)

Overproduction of the Bradyrhizobium japonicum c-type cytochrome subunits of the $c b b_{3}$ oxidase in Escherichia coli. Biochem. Biophys. Res. Comm. 251, 744-747

16. Sanders, C., and Lill, H. (2000) Expression of prokaryotic and eukaryotic cytochromes $c$ in Escherichia coli. Biochim. Biophys. Acta 1459, 131-138

17. Barker, P. D., Bertini, I., Del Conte, R., Ferguson, S. J., Hajieva, P., Tomlinson, E., Turano, P., and Viezzoli, M. S. (2001) A further clue to understanding the mobility of mitochondrial yeast cytochrome $c$ : a ${ }^{15} \mathrm{~N} T_{1 \rho}$ investigation of the oxidized and reduced species. Eur. J. Biochem. 268, 4468-4476

18. Allen, J. W. A. and S. J. Ferguson, S. J. (2006) What is the substrate specificity of the System I cytochrome c biogenesis apparatus? Biochem. Soc. Trans. 34, 150-151

19. Allen, J. W. A., Tomlinson, E. J., Hong, L., and Ferguson, S. J. (2002) The Escherichia coli cytochrome $c$ maturation $(\mathrm{Ccm})$ system does not detectably attach heme to single cysteine variants of an apocytochrome $c$. J. Biol. Chem. 277, 33559-33563

20. Allen, J. W. A., Ginger, M. L., and Ferguson, S. J. (2004) Maturation of the unusual singlecysteine $(\mathrm{XXXCH})$ mitochondrial $c$-type cytochromes found in trypanosomatids must occur through a novel biogenesis pathway. Biochem. J. 383, 537-542

21. Devreese, B., Brigé, A, Backers, K., van Driessche, G., Mayer, T. E., Cusanovich, M. A., and van Beeumen, J. J. (2000) Primary structure characterization of a Rhodocyclus tenuis diheme cytochrome $c$ reveals the existence of two different classes of low-potential diheme cytochromes $c$ in purple phototropic bacteria. Arch. Biochem. Biophys. 381, 53-60

22. D. Aragao, C. Frazao, L. Sieker, G. M. Sheldrick, J. LeGall, M. A. Carrondo (2003) Structure of dimeric cytochrome $c_{3}$ from Desulfovibrio gigas at $1.2 \AA$ resolution. Acta Crystallogr. D Biol. Crystallogr. 59, 644-653

23. Ríos-Velázquez, C., Cox, R. L. and Donohue, T. J. (2001) Characterization of Rhodobacter sphaeroides cytochrome $c^{2}$ proteins with altered heme attachment sites. Arch. Biochem. Biophys. 389, 234-244

24. Hussain, H., Grove, J., Griffiths, L., Busby, S., and Cole, J. (1994) A seven-gene operon essential for formate-dependent nitrite reduction to ammonia by enteric bacteria. Mol. Micro. 12, $153-163$

25. Riddles, P. W., Blakeley, R. L., and Zerner, B. (1983) Reassessment of Ellman's reagent. Methods Enzymol. 91, 49-60

26. Bartsch, R. G. (1971) Cytochromes: bacteria. Methods Enzymol. 23, 344-363

27. Rai, D. K., Griffiths, W. J., Landin, B., Wild, B. J., Alvelius, G., and Green, B. N. (2003) Accurate mass measurement by electrospray ionization quadrupole mass spectrometry: detection of variants differing by $<6$ Da from normal in human hemoglobin heterozygotes. Anal. Chem. 75, 1978-1982 
28. Rice, J. K., Fearnley, I.M. and Barker, P.D. (1999). Coupled oxidation of heme covalently attached to cytochrome $b_{562}$ : towards conversion of a cytochrome to a photoreceptor. Biochemistry 38, 16847-16856

29. Allen J. W. A., Barker P. D., Daltrop O., Stevens J. M., Tomlinson E. J., Sinha N., Sambongi Y. and Ferguson S.J. (2005) Why isn't 'standard' heme good enough for $c$-type and $d_{1}$-type cytochromes? Dalton Transactions, 3410-3418

30. Daltrop, O., Allen, J. W. A., Willis, A. C. and Ferguson, S. J. (2002) In vitro formation of a c-type cytochrome. Proc. Nat. Acad. Sci. USA 99, 7872-7876

31. Barker, P. D., Ferrer, J. C., Mylrajan, M., Loehr, T. M., Feng, R., Konishi, Y., Funk, W. D., MacGillivray, R. T. and Mauk, A. G. (1993) Transmutation of a heme protein. Proc. Nat. Acad. Sci. USA 90, 6542-6546

32. Fee, J. A., Todaro, T. R., Luna, E., Sanders, D., Hunsicker-Wang, L. M., Patel, K. M., Bren, K. L., Gomez-Moran, E., Hill, M. G., Ai, J., Loehr, T. M., Oertling, W. A., Williams, P. A., Stout, C. D., McRee, D. and Pastuszyn, A. (2004) Cytochrome $\mathrm{rC}_{552}$, formed during expression of the truncated, Thermus thermophilus cytochrome $c_{552}$ gene in the cytoplasm of Escherichia coli, reacts spontaneously to form protein-bound 2-formyl-4-vinyl (Spirographis) heme.

Biochemistry 43, 12162-12176

33. Keightley, J. A., Sanders, D., Todaro, T. R., Pastuszyn, A, and Fee, J. A. (1998) Cloning and expression in Escherichia coli of the cytochrome $C_{552}$ gene from Thermus thermophilus HB8. Evidence for genetic linkage to an ATP-binding cassette protein and initial characterization of the cycA gene products. J. Biol. Chem. 273, 12006-12016

34. Hartshorne, R. S., Kern, M., Meyer, B., Clarke, T. A., Karas, M., Richardson, D. J., and Simon, J. (2007) A dedicated haem lyase is required for the maturation of a novel bacterial cytochrome $c$ with unconventional covalent haem binding. Mol. Microbiol. 64, 1049-1060. 


\section{Figure Legends}

Figure 1. Absorption spectra of $c$-type cytochrome variants of $E$. coli cytochrome $b_{562}$ with extra cysteines in or around the heme-binding motif. Representative examples are shown. (A) Cytochrome $b_{562} \mathrm{CXCCH}(\mathrm{R} 98 \mathrm{C} / \mathrm{A} 100 \mathrm{C} / \mathrm{Y} 101 \mathrm{C})$ matured in the presence (solid line) or absence (dotted line) of the $E$. coli $\mathrm{Ccm}$ proteins expressed from plasmid pEC86, and cytochrome $b_{562}$ $\mathrm{CCXXCH}$ (T97C/R98C/Y101C) matured in the presence (dashed line) or absence (dash-dotdash) of the $\mathrm{Ccm}$ proteins. Variants with $\mathrm{CCXCH}$ and $\mathrm{CXXCHC}$ heme-binding motifs gave very similar spectra (not shown). The spectra are of unpurified periplasmic extracts of $E$. coli expressing the respective cytochromes and were recorded at $25^{\circ} \mathrm{C}$ following the addition of a few grains of disodium dithionite to the cytochromes in $100 \mathrm{mM}$ Tris- $\mathrm{HCl}, \mathrm{pH} 8.0,0.5 \mathrm{mM}$ EDTA and $0.25 \mathrm{M}$ sucrose. Absorption maxima are given in Table 1 . The spectra were normalised assuming an $\alpha$-band extinction coefficient of $25,800 \mathrm{M}^{-1} \mathrm{~cm}^{-1}$ for the cytochromes expressed in the absence of the Ccm proteins and 22,900 $\mathrm{M}^{-1} \mathrm{~cm}^{-1}$ for those expressed in their presence. These were the values for Components I and II of the cytochrome $b_{562} \mathrm{R} 98 \mathrm{C} / \mathrm{Y} 101 \mathrm{C}$ variant characterised by Barker et al. $[12,13]$. (B) Reduced pyridine hemochrome spectra of the same cytochrome-containing periplasmic extracts. Final concentrations of sodium hydroxide and pyridine were $0.2 \mathrm{M}$ and $30 \%(\mathrm{v} / \mathrm{v})$ respectively. The vertical line is at $550 \mathrm{~nm}$. Since no extinction coefficients are available, these spectra were normalised by $\alpha$-band intensity.

Figure 2. (A) Absorption spectra of $c$-type cytochrome variants of $E$. coli cytochrome $b_{562}$ with $\mathrm{CX}_{3} \mathrm{CH}$ (solid line), $\mathrm{CX}_{4} \mathrm{CH}$ (dashed line), $\mathrm{CX}_{5} \mathrm{CH}$ (dotted line) or $\mathrm{CX}_{6} \mathrm{CH}$ (dot-dash-dot) heme binding motifs matured by the E. coli Ccm proteins expressed from plasmid pEC86. Spectra were recorded at $25{ }^{\circ} \mathrm{C}$ following the addition of a few grains of disodium dithionite to reduce the purified cytochromes. The proteins were buffered in $10 \mathrm{mM}$ Tris- $\mathrm{HCl}, \mathrm{pH} \mathrm{8.0.} \mathrm{The} \mathrm{spectra}$ were normalised assuming that all the proteins have the same Soret band extinction coefficient; spectral maxima are given in Table 2. Inset: Reduced pyridine hemochrome spectra of the purified cytochromes. Final concentrations of sodium hydroxide and pyridine were $0.2 \mathrm{M}$ and $30 \%(\mathrm{v} / \mathrm{v})$ respectively. The vertical line is at $550 \mathrm{~nm}$, and the spectra were normalised by $\alpha-$ band intensity. (B) Reduced pyridine hemochrome spectra of $c$-type cytochrome variants of $E$. coli cytochrome $b_{562}$ with $\mathrm{CX}_{5} \mathrm{CH}$ (dotted line) or $\mathrm{CX}_{6} \mathrm{CH}$ (dashed line) heme-binding motifs matured in the absence of the $\mathrm{Ccm}$ proteins. For comparison, the spectrum of cytochrome $b_{562}$ $\mathrm{CX}_{5} \mathrm{CH}$ matured in the presence of the $\mathrm{Ccm}$ proteins is shown (solid line). The spectra were normalised by $\alpha$-band intensity.

Figure 3. NMR spectra of reduced (Fe(II)) cytochrome $b_{562} \mathrm{CCXXCH}$ isolated and purified as described in the Experimental section after expression in E. coli with co-expression of the $\mathrm{ccm}$ genes from plasmid pEC86. (A) $1 \mathrm{D}^{1} \mathrm{H}$ NMR spectrum at $500 \mathrm{MHz}$. The heme meso proton resonances are labelled, as are the resonances of the $\varepsilon$-methyl protons of the heme iron ligand Met-7. Resonances highlighted with an asterisk are from Met-7 $\varepsilon$-methyl protons in minor species with an unknown modification. (B) A section of the ${ }^{1} \mathrm{H}-\mathrm{NOESY}$ spectrum of the same sample as in (A). The NOESY couplings used to assign the heme protons are shown. Highlighted in the expanded region (inset) are the TOCSY cross-peaks from the 2- and 4methine and methyl heme substituents that result from the reaction of the cysteine residues of the apocytochrome cCXXCH heme-binding motif with the heme 2- and 4- vinyl groups. There is no heterogeneity revealed in this region of the spectrum and the chemical shifts of the relevant protons are very close to those reported in our earlier work for $\mathrm{Ccm}$ matured cytochrome $b_{562}$ CXXCH (Component II) [12, 13], which has the same stereo- and regio-specific covalent attachment of heme as is observed in all natural $c$-type cytochromes for which structural data are available. 
Table 1. Spectroscopic data for maturation of cytochrome $b_{562}$ variants with three cysteines around the heme-binding motif.

\begin{tabular}{|c|c|c|c|c|}
\hline $\boldsymbol{b}_{\mathbf{5 6 2} \text { variant }}$ & $\begin{array}{c}\text { +/- Ccm system } \\
\text { (from pEC86) }\end{array}$ & $\begin{array}{c}\text { Absorption } \\
\text { maxima (nm) }\end{array}$ & $\begin{array}{c}\text { Pyridine } \\
\text { hemochrome } \\
\text { maximum (nm) }\end{array}$ & $\begin{array}{c}\text { Yield (mg } \\
\text { holocytochrome } \\
\text { per gram of wet } \\
\text { cells) }\end{array}$ \\
\hline $\mathrm{CCXXCH}$ & + & $526.0,555.5$ & 549.9 & 5.2 \\
\hline $\mathrm{CCXXCH}$ & - & $528.2,558.2$ & 552.1 & 2.6 \\
\hline $\mathrm{CCXCH}$ & + & $526.0,556.0$ & 549.8 & 5.5 \\
\hline $\mathrm{CCXCH}$ & - & $529.9,560.1$ & 553.0 & 1.8 \\
\hline $\mathrm{CXCCH}$ & + & $526.0,556.0$ & 549.9 & 5.4 \\
\hline $\mathrm{CXCCH}$ & - & $528.7,558.8$ & 552.1 & 5.8 \\
\hline $\mathrm{CXXCHC}$ & + & $526.0,556.0$ & 549.8 & 1.5 \\
\hline $\mathrm{CXXCHC}$ & - & $528.7,559.0$ & 552.5 & \\
\hline
\end{tabular}


Table 2. Spectroscopic and mass spectrometric data for maturation of the cytochrome $b_{562}$ variants in the series $\mathrm{CX}_{n} \mathrm{CH}$. n.d. = not determined. Percentages indicate the approximate amount of the given cytochrome $b_{562}$ variant with each mass detected in the ESI-MS experiment (see also the main text for details).

\begin{tabular}{|c|c|c|c|c|c|c|}
\hline $\begin{array}{c}b_{562} \\
\text { variant }\end{array}$ & $\begin{array}{c}+/- \\
\text { Ccm } \\
\text { system } \\
\text { (from } \\
\text { pEC86) }\end{array}$ & $\begin{array}{l}\text { Absorption } \\
\text { maxima } \\
\text { (nm) }\end{array}$ & $\begin{array}{c}\text { Pyridine } \\
\text { hemochrome } \\
\text { maximum } \\
(\mathbf{n m})\end{array}$ & $\begin{array}{c}\text { Yield (mg } \\
\text { holocytochrome } \\
\text { per gram of wet } \\
\text { cells) }\end{array}$ & $\begin{array}{c}\text { Calculated } \\
\text { molecular } \\
\text { mass }\end{array}$ & $\begin{array}{l}\text { Observed } \\
\text { mass(es) } \\
\text { by ESI- } \\
\text { MS }\end{array}$ \\
\hline $\begin{array}{l}\mathrm{CXXCH} \\
\text { [Ref 13] }\end{array}$ & + & $\begin{array}{l}525.5, \\
555.5\end{array}$ & 549.5 & & 12284 & 12282 \\
\hline $\mathrm{CX}_{3} \mathrm{CH}$ & + & $\begin{array}{l}525.7, \\
555.1\end{array}$ & 550.0 & 3.7 & 12355 & 12354 \\
\hline $\mathrm{CX}_{4} \mathrm{CH}$ & + & $\begin{array}{l}525.1, \\
555.4\end{array}$ & 548.9 & & 12412 & 12410 \\
\hline $\mathrm{CX}_{5} \mathrm{CH}$ & + & $\begin{array}{l}525.6, \\
555.0\end{array}$ & 549.6 & & 12499 & $\begin{array}{c}12498 \\
(\sim 60 \%) \\
12530 \\
(\sim 11 \%) \\
12562 \\
(\sim 31 \%)\end{array}$ \\
\hline $\mathrm{CX}_{5} \mathrm{CH}$ & - & $\begin{array}{c}526.3, \\
556.0\end{array}$ & 55 & 0.36 & & n.d. \\
\hline $\mathrm{CX}_{6} \mathrm{CH}$ & + & $\begin{array}{l}525.8, \\
555.2\end{array}$ & 549.8 & 1.7 & 12627 & $\begin{array}{c}12658 \\
(\sim 14 \%) \\
12674 \\
(\sim 32 \%) \\
12690 \\
(\sim 54 \%)\end{array}$ \\
\hline $\mathrm{CX}_{6} \mathrm{CH}$ & - & 527.0 , & 551.9 & 0.26 & & n.d. \\
\hline
\end{tabular}



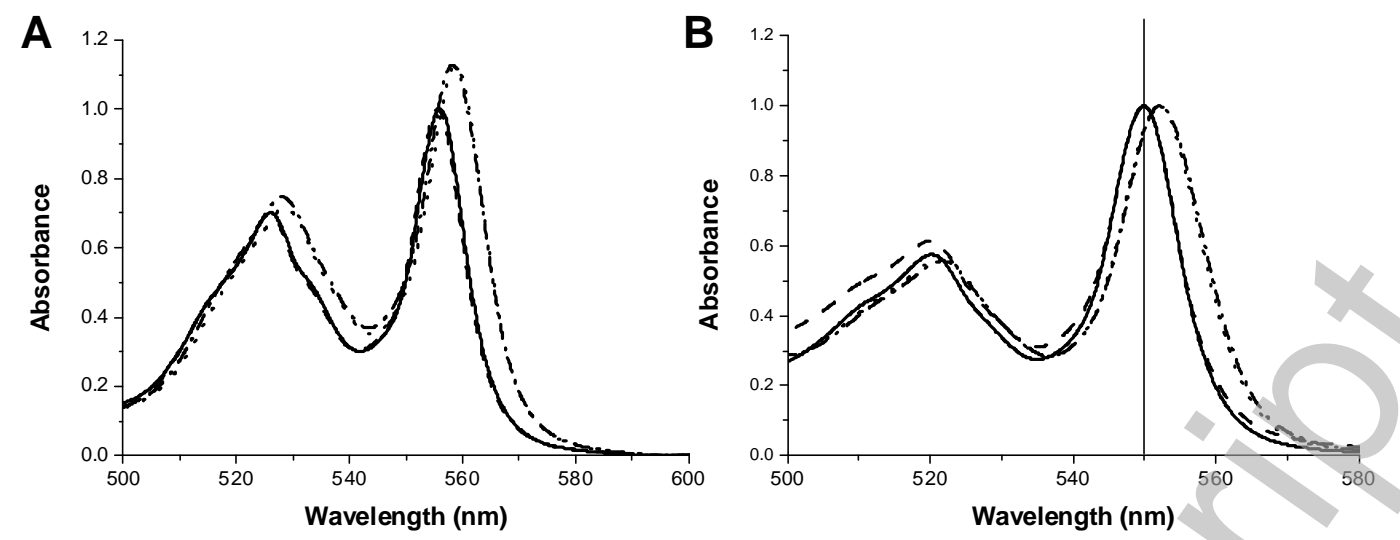

Figure 1 

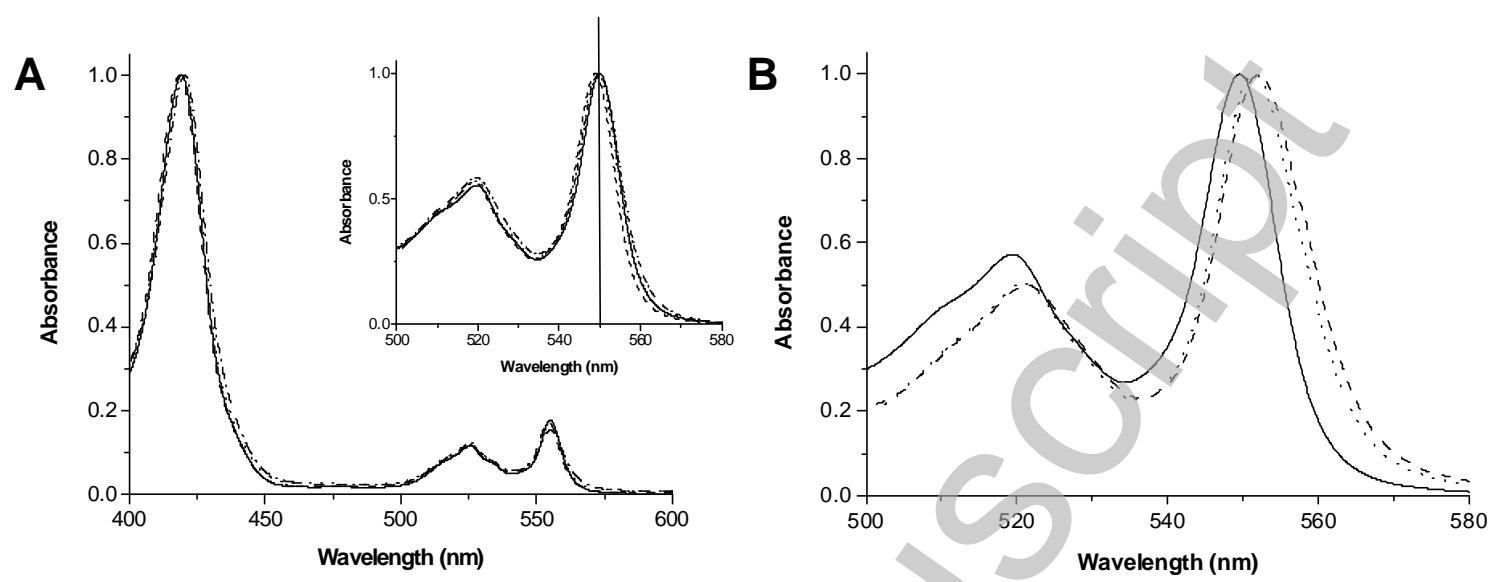

Figure 2 
A

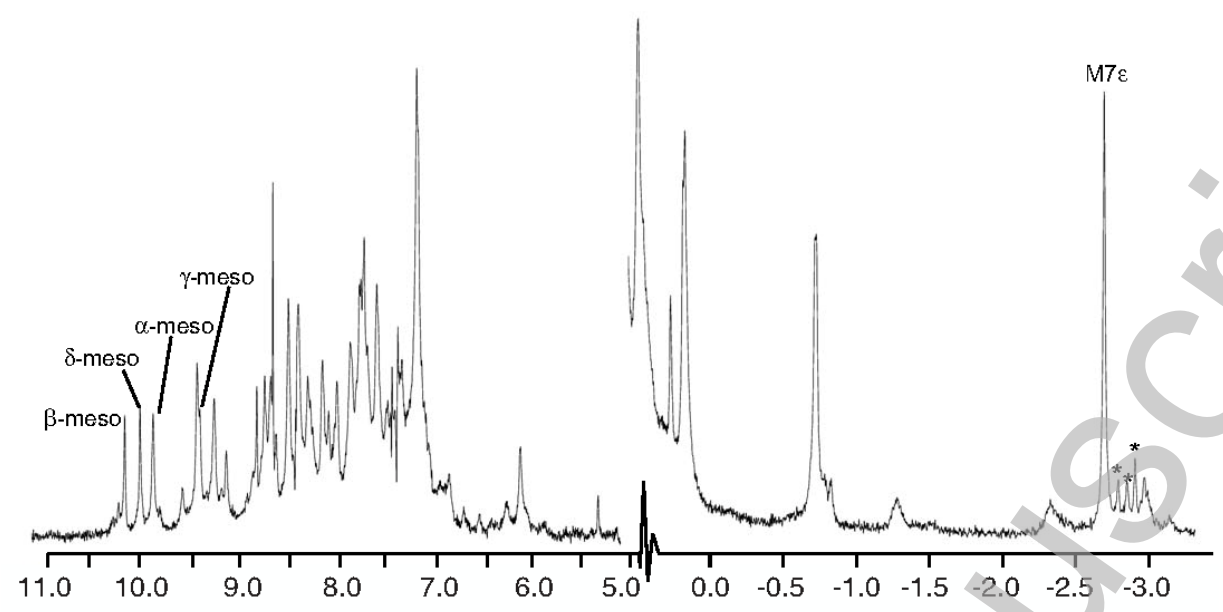

$\omega_{2}-{ }^{1} \mathrm{H}(\mathrm{ppm})$

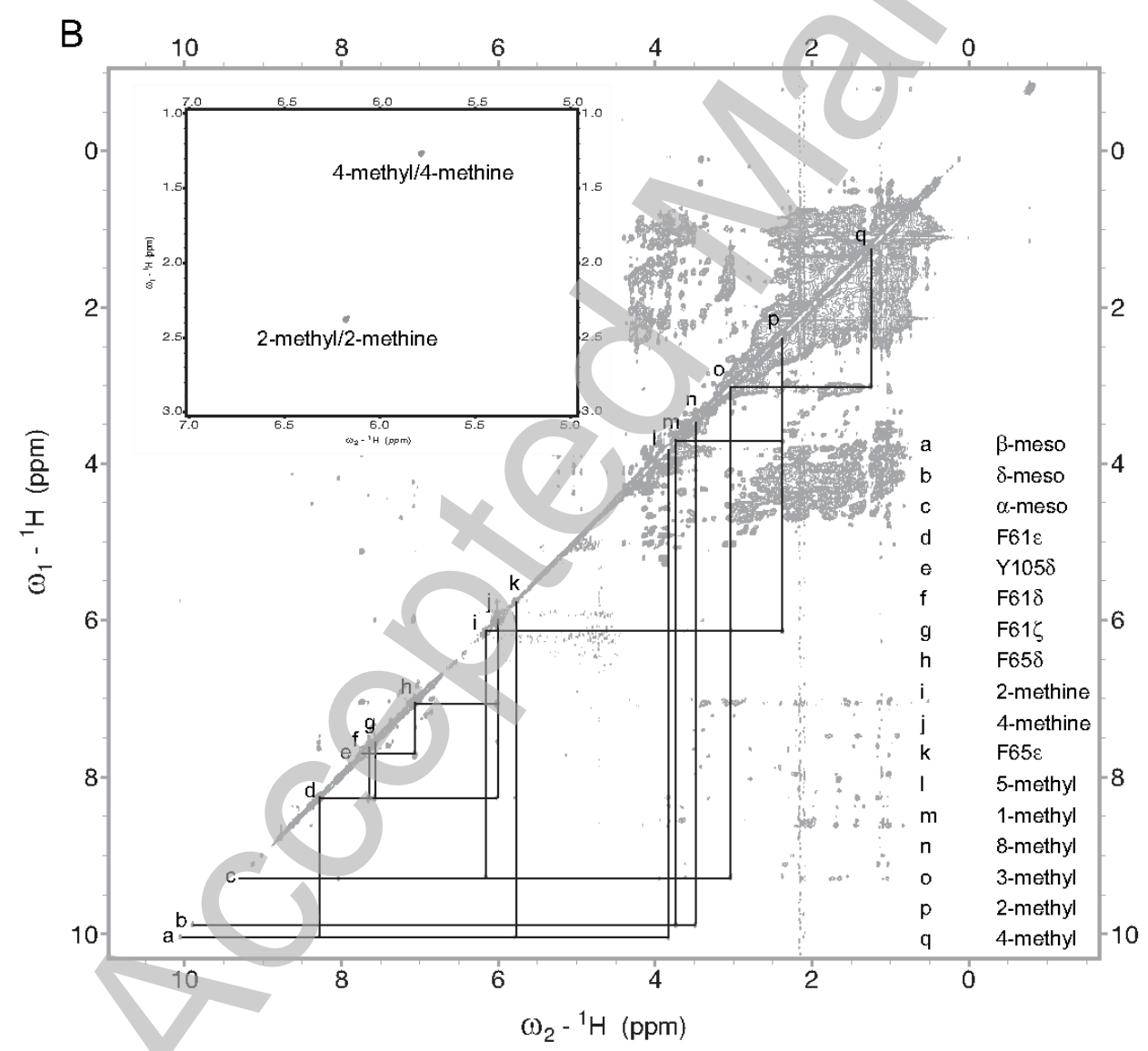

Figure 3

Licenced copy. Copying is not permitted, except with prior permission and as allowed by law. (C) 2008 The Authors Journal compilation (c) 2008 Portland Press Limited 